\title{
Optimal algorithm for on-grid PV units disconnection to mitigate the grid congestion
}

\author{
Safaa. M. Emara ${ }^{\mathrm{a}}$, Ayman. M. Soliman ${ }^{\mathrm{b}}$, Mohamed. S. El-bages ${ }^{\mathrm{c}}$, Ebtisam. M. \\ Saied $^{\mathrm{d}}$ and Mohamed. M. Salama ${ }^{\mathrm{e}}{ }^{\mathrm{a}^{*}}$ \\ ${ }^{a, b}$ Department of Power Electronics and Energy Conversion, Electronics Research Institute (ERI), Giza, Egypt \\ ${ }^{c, d, e}$ Department of Electrical Engineering, Shoubra Faculty of Engineering, Benha University, cairo, Egypt
}

\begin{abstract}
Grid congestion problem is a state where the current transmission and/or distribution lines are not capable to fit in with needs of all required load. Congestion is often appeared in high-demand areas, and at places where plentiful renewable energy is generated and injected into the grid. In this paper, the congestion problem resulting from the PV systems surpluses can be relieved by disconnecting one or more PV consumer from the grid. The objective of the paper is maximizing the number of connected units on the grid with minimal tariffs subject to the power capacity constraint. The PV surplus congestion will be manipulated as a 0/1 Knapsack Problem and resolve it with Greedy Algorithm (GA). The objective of the GA is to find the most influential consumer as candidate consumer for the disconnection. The performance is compared with Particle Swarm Optimization Technique (PSO). From the comparison the PSO gave better optimization for selecting the consumer to be disconnected. By disconnecting the selected units the solar units may continue to supply power to the load. This is known as an island, islanding is not permitted for its relative problem. Avoiding this mode can be done straight forward by proposed canceling the disconnection process for the selected PV units and controlling its output power. This will be investigated as a future work.
\end{abstract}

Keywords: Network Congestion, On-Grid PV Surpluses, Greedy Algorithm, Knapsack Problem, Particle Swarm Optimization Technique (PSO).

\section{Introduction}

Congestion is an event where there is insufficient capacity to transport all dealings at the same time due to a small number of unforeseen emergencies [1]. Generally, it appears in both regulated and deregulated power systems but, but occurs more often in deregulated ones because of opposition among energy producers and consumers[2]. Also, networks congestion may occur by the penetration of Distributed Energy Resources (DERs) at load bus such as (PV systems), wind power systems (WPS), Electric Vehicle (EV) and heat pump (HP) in which this penetration represents a big challenge to the grid planners and operators. The congestion may appear in several ways: Weak coordination between generation and transport utilities, sudden increase in demand, power surpluses created by installed Distributed Generation (DG) units [3].Congestion management is one of the technical challenges in power system. The objective of managing the congestion is to take control actions for relieving congestion of power transmission networks [4]. The congestion management methods for distribution networks can be grouped into two categories: indirect control methods and direct control methods [5]. The indirect group consists of dynamic tariff, distribution capacities and shadow price. The direct control group consists of system reconfiguration, control of reactive power and control of active power [5]. Optimal location of the generators and scaled power system networks has been reviewed in [6] as a system reconfiguration for maximizing the congestion relieving in which the appropriate size and location of the generating unit are necessary. Some of the

\footnotetext{
* Manuscript received June 4, 2018; revised March 21, 2019.

Corresponding author.E-mail address: Safaa.Mohamed@eri.sci.eg.

doi: 10.12720 /sgce.8.3.332-340
} 
available congestion management techniques based on power flow tracing approach for selection and generation rescheduling have been presented in [7]-[8]. In [9] the optimal rescheduling of active power of generators utilizing Particle Swarm Optimization (PSO) and Chaotic Particle Swarm Optimization (CPSO) has been solved. Other option to manage congestion is to operating Flexible AC Transmission System (FACTS) devices on transmission lines. This operation of FACTS devices considers both technical and economic considerations which are presented in [10]-[11]. Congestion in the transmission lines can be mitigated by operation and planning of connected DG systems [2]. Recently, the congestion was studied due to the inverse power of solar panels in the distribution network especially after creation of feed-in tariff policy. This policy is introduced to develop active investment in renewable energy sources. It provides an assured best price to the green electricity producer and put an obligation on the grid operators to buy the generated electricity output [12]. In Egypt the electrical distribution companies are committed to buy the produced electricity from renewable energy power plants at the prices declared, 25 years for the PV plants and 20 years in the wind plants [13]. The feed-in tariff for the PV scheme from the generated power capacity point of view is divided as follows:

- Regulations for implementation of Renewable Energy Feed-in Tariff projects up to $500 \mathrm{~kW}$.

- Regulations for implementation of Renewable Energy Feed-in Tariff projects above $500 \mathrm{~kW}$.

In this paper the congestion problem resulting from a surplus of solar power is formulated as one type of knapsack problems (KPs). Selection techniques of disconnecting solar units are proposed. Heuristic algorithms for unit selection based on Greedy Algorithm (AG) and Particle Swarm Optimization algorithm are proposed (PSO).

The rest of the article is organized as follows: Section 2 discusses one type of KP. Section 3 formulates the congestion problem and greedy approach. Section 4 analyses the case study simulation results of the proposed algorithm. In section 5 Particle Swarm Optimization (PSO) algorithm is proposed for unit selection. Section 6 summarizes the main points and a conclusion.

\section{Knapsack Problem-KP}

Knapsack problem is a combinational optimization problem which has been studied widely during the past four decades [14]-[15]. In such problems, the objective is to maximize (or minimize) some quantity while satisfying some constraints. The KP can be presented as follows: 'suppose taking a trip by carrying a backpack which has a certain capacity. Given a set of elements, each element has some weight and some value, define the number of each element to include in a backpack in which the total weight is less than a certain limit and the total value is as much as possible'[16].

Vector $\mathrm{w}=\left(\mathrm{w}_{1}, \mathrm{w}_{2}, \ldots, \mathrm{w}_{\mathrm{n}}\right)$ contains $\mathrm{n}$ items' weights, and other vector $\mathrm{v}=\left(\mathrm{v}_{1}, \mathrm{v}_{2}, \ldots, \mathrm{v}_{\mathrm{n}}\right)$ contains their values, where $\mathrm{v}_{\mathrm{i}}$ and $\mathrm{w}_{\mathrm{i}}$ are integers. To find other $\mathrm{n}$-dimension decision vector $\mathrm{x}=\left(\mathrm{x}_{1}, \mathrm{x}_{2}, \ldots, \mathrm{x}_{\mathrm{n}}\right)$ make the total maximum value under the limit of knapsack. The related math equation can be described as following:

Maximize:

$\sum_{\mathrm{i}=1}^{\mathrm{n}} \mathrm{v}_{\mathrm{i}} \mathrm{x}_{\mathrm{i}}$

Subject .to:

$\sum_{\mathrm{i}=1}^{\mathrm{n}} \mathrm{w}_{\mathrm{i}} \mathrm{x}_{\mathrm{i}} \leq \mathrm{W}$

$\mathrm{x}_{\mathrm{i}} \in\{0,1\}, \quad \mathrm{i}=1,2, \ldots, \mathrm{n}$

The $i^{\text {th }}$ item is put into knapsack if $x_{i}=1$, the $i^{\text {th }}$ item is not put into knapsack if $x_{i}=0$. So, the problem called the 0-1 KP. In this problem, fraction amount cannot be taken where the items must be taken or left totally.

\section{Problem Formulation and Proposed Knapsack Greedy Algorithm}

We consider $\mathrm{N}$ client with installed PV solar units. Each client is symbolized by $\mathrm{n}, \mathrm{n}=1,2, \ldots, \mathrm{N}$, and its $\mathrm{PV}$ unit is symbolized by $\mathrm{X}_{\mathrm{n}}$., the client $\mathrm{n}$ may (not) consume power in KW through solar power generation, its demand symbolized by $P_{D, n}$. The power surplus from PV unit $X_{n}$ is (not) found when the produced PV power in $\mathrm{kW}$ is (lower) greater than its need, the surplus is an integer and symbolized by $\mathrm{P}_{\mathrm{S}, \mathrm{n}}$. 
In the distribution grid, the congestion issue can be considered as a type of KPs whereby the client either remains joined to the grid or disjointed from the grid. Therefore, we take a 0/1 KP in which the client $\mathrm{n}$ is off the grid the $X_{n}=0$ and the client $n$ is on the grid the $X_{n}=1$. Then, the total number of joined clients can be calculated:

$$
\mathrm{U}=\sum \mathrm{X}_{\mathrm{n}}, \quad \mathrm{X}_{\mathrm{n}} \in\{0,1\}
$$

The goal is to maximize the number of joined clients corresponding to a certain capacity that the grid can accommodate the surpluses of joined clients.

Maximize: $\sum \mathrm{X}_{\mathrm{n}}$

$$
\text { Subject .to: } \sum \mathrm{P}_{\mathrm{s}, \mathrm{n}} \cdot \mathrm{X}_{\mathrm{n}} \leq \mathrm{P}_{\mathrm{ATC}}, \quad \mathrm{x}_{\mathrm{n}} \in\{0,1\}
$$

From power point of view, when a large number of clients joined to the grid a large number of clients can be sell the power surplus to the grid while using their own solar power. Our target is to maximize the value of total power demand while meeting the capacity requirement.

$$
\begin{aligned}
& \operatorname{Max}: \sum P_{D, n} \cdot X_{n} \\
& \text { S.t: } \quad \sum P_{s, n} \cdot X_{n} \leq P_{\text {ATC }}, \quad x_{n} \in\{0,1\}
\end{aligned}
$$

Residual capacity of the physical transmission network is measured by the index (ATC) 'Available Transfer Capability' [17]. It has been implemented to manage congestion for power marketers business in competitive electricity market. The ATC value is given by:

$$
\text { ATC }=\text { TTC-TRM-CBM-ETC }
$$

The Total Transfer Capability (TTC) is the maximum quantity of energy that can be passed over the grid in a reliable way while satisfying all safety constraints (i.e. voltage, thermal and stability boundary). Transmission Reliability Margin (TRM) is the quantity of transmission capacity to guarantee the grid is safe under reasonable limits of uncertainties in network conditions and (ETC) Existing Transmission Commitments, Capacity Benefit Margin (CBM) is the quantity of transmission transfer capability booked up by load serving entities for generation reliability requirements, it is booked up for emergency when energy generation is not enough in one zone which needs to be provided with purchased energy from other zones [18].

From studying and expectation for the future after spreading the feed-in tariff policy, selling of power surplus will be by auctions. This means, the clients with lower tariff will remain connected, the higher are disconnected. Consequently, the proposed algorithm will achieve the ultimate target of having less power surplus flowing to the network, more units joined to the grid and minimum tariff for the joined units. Greedy Algorithm is proposed to solve the KP.

Fig. 1 shows the flow chart of the GA in which data about the ATC and clients (number of clients (PV units), surpluses and tariff) is fed in (step 1). While the network is not congested no clients are disconnected. The (overload) congested condition of the network is calculated by subtracting the capacity boundary from the total surplus of $\mathrm{N}$ clients.

$$
\mathrm{P}_{\mathrm{o}}=\sum \mathrm{P}_{\mathrm{s}, \mathrm{n}}-\mathrm{P}_{\mathrm{ATC}}
$$

By discovering the congestion (i.e. $\mathrm{P}_{\mathrm{O}}>0$ ), the surpluses are arranged in ascending order. 


$$
\mathrm{P}_{\mathrm{S}, 1} \leq \mathrm{P}_{\mathrm{S}, 2} \quad \ldots \ldots \leq \mathrm{P}_{\mathrm{S}, \mathrm{n}} \quad \mathrm{n} \in \mathrm{N}
$$

If $\mathrm{P}_{\text {АTC }}$ more than the minimum surpluses, searching for split unit (step 2). Units are selected based on their surpluses in ascending order. The algorithm will stop when an overload of the capacity is found, i.e.

$$
\sum_{\mathrm{n}=1}^{\mathrm{s}-1} \mathrm{P}_{\mathrm{s}, \mathrm{n}} \leq \mathrm{P}_{\mathrm{ATC}} \text { and } \sum_{\mathrm{n}=1}^{\mathrm{s}} \mathrm{P}_{\mathrm{s}, \mathrm{n}}>\mathrm{P}_{\mathrm{ATC}}, \mathrm{n}=1,2,
$$

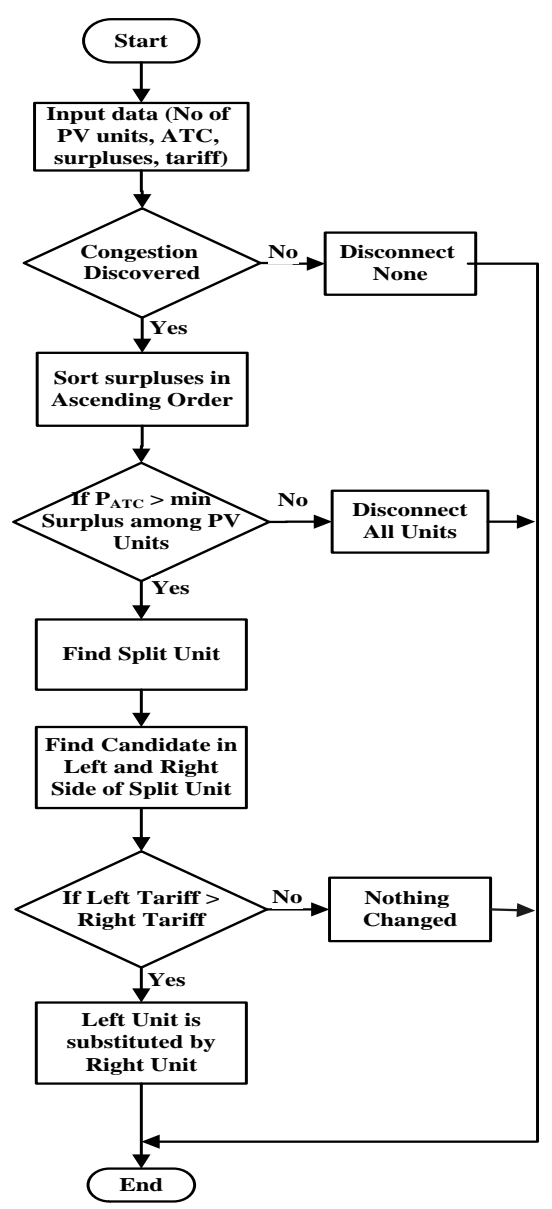

Fig. 1. Flow chart for proposed knapsack greedy algorithm

Observe that the capacity constraint will be exceeded if the $\mathrm{P}_{\mathrm{S}, \mathrm{s}}$ was added, $\mathrm{P}_{\mathrm{S}, \mathrm{s}}$ is the split surplus value. Unit (client) $S$ is set to be the split one, which divided the solution with $\mathbf{x}=1$ for $\mathrm{n}=1 ; 2$; -1 (left) and $\mathrm{x}=0$ for $\mathrm{n}=\mathrm{s} ; \mathrm{s}+1 ; \ldots ; \mathrm{N}$ (right).

$$
\begin{array}{rlrrrr}
X & =\left[\begin{array}{llllll}
\mathrm{x}_{1} & \mathrm{X}_{2} & \mathrm{X}_{\mathrm{s}-1} & \mathrm{X}_{\mathrm{s}} & \mathrm{X}_{\mathrm{s}+1} & \mathrm{X}_{\mathrm{N}}
\end{array}\right] \\
& =\left[\begin{array}{llllll}
1 & 1 & 1 & 0 & 0 & 0
\end{array}\right]
\end{array}
$$

By adding the split surplus value the overflowed power $\left(\mathrm{P}_{\mathrm{E}}\right)$ will be known, which is incorporated into the two conditions specified in step 3. The number of candidate units in left and right of split unit will be considered for a one-to-one substitution.

$$
\mathrm{P}_{\mathrm{E}}=\sum_{\mathrm{n}=1}^{\mathrm{s}} \mathrm{P}_{\mathrm{s}, \mathrm{n}}-\mathrm{P}_{\mathrm{ATC}}
$$


Step. 1 (Sort surpluses in ascending order)

1: Inter the number of units, available transfer capability, surpluses in each unit, tariff of each unit.

2: Determine if the capacity is overloaded $\%$ (Eq. 5)

3: if $\mathrm{P}_{\mathrm{O}} \leq 0$ then

4: Disconnect none

5: else

6: Sort surpluses in ascending order

\section{Step. 2 (find split unit)}

7: if $\mathrm{P}_{\text {ATC }}>$ the min surplus amongst $\mathrm{N}$ units then

8: $\mathrm{Z}=\mathrm{P}_{\mathrm{ATC}}$

9: $\quad$ for $i=1$ to $\mathrm{N}$ do

10: $\quad$ if $\mathrm{P}_{\mathrm{S} ; i} \leq \mathrm{Z}$ then

11: $\quad \mathrm{Z}=\mathrm{Z}-\mathrm{P}_{\mathrm{S} ; i}$

$\%$ Keep unit $i \mathrm{ON}$

12: $\quad$ else

13: No more units can be accommodated

14: $\mathrm{s}=i$

$\%$ split unit

15: end if

16: end for

Step. 3 (Discover candidate( $(s)$ )

17: $\mathrm{c}=\mathrm{s}-1$

18: Compute the overflowed power $\mathrm{P}_{\mathrm{E}}$

$\%($ Eq. 8$)$

19: for $\mathrm{w}=1$ to $\mathrm{c}$ do

20: Find candidate(s) in left side $\left(\mathrm{x}_{\text {left }}\right)$

21: if $\mathrm{P}_{\mathrm{E}} \leq \mathrm{P}_{\mathrm{S}, \mathrm{w}}$ then

22: $\quad$ One in left side among units $\mathrm{w}-(\mathrm{s}-1)$ with min tariff is the candidate.

23: $\quad$ for $\mathrm{k}=\mathrm{s}+1$ to $\mathrm{N}$ do

24: $\quad$ Find candidate $(\mathrm{s})$ in right side $\left(\mathrm{x}_{\text {right }}\right)$

25: $\quad$ if $\mathrm{P}_{\mathrm{S} ; \mathrm{k}}-\mathrm{P}_{\mathrm{S} ; \mathrm{s}} \leq \mathrm{P}_{\mathrm{S} ; \text { left }}-\mathrm{P}_{\mathrm{E}}$ then

26: $\quad$ One in right side among units $\mathrm{s}-(\mathrm{k}-1)$ with minimum tariff is the candidate

27: $\quad$ if tariff left $_{\text {i }}>$ tariff right then

28: $\quad$ Unit left is substituted by unit right

29: $\quad$ end if

30: $\quad$ end if

$\%$ Nothing changed otherwise

31: end for

32: $\quad$ end if

33: end for

34: end if

35: end if

$\%$ Disconnect all otherwise 


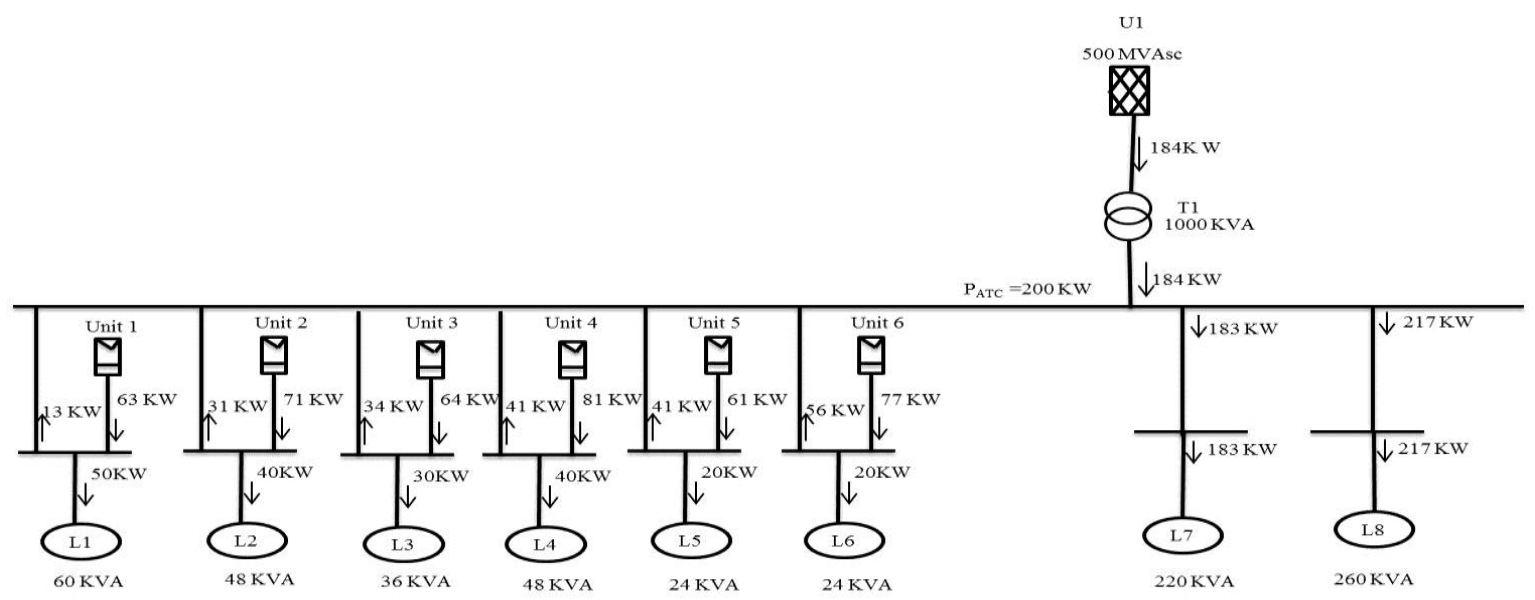

Fig. 2. Case study load flow

\section{Case Study}

By using the Electrical Transient Analyzer Program (ETAP), a case study had been modeled for consumer demand of $600 \mathrm{kw}$ (8consumers) feeding from power transformer (1000KVA), six of consumers with load power $(200 \mathrm{kw})$ owned PV units accommodate to ATC (200kw) as in Fig.2. When load flow of the system is implemented, the power of the PV units can meet the load of consumers. The excess power (surpluses $=216 \mathrm{kw}$ ) can return to the grid to feed other users. The line capacity cannot accommodate the residual surpluses which is exceed the ATC value, disconnecting some of the consumer is the proper approach for congestion avoidance by applying the proposed knapsack GA. At the beginning the information about $\mathrm{N}$ clients owned PV units has been collected (surpluses in KW, the ATC in KW and the tariff in pilasters). No units are disconnected while the network is not overloaded. By discovering the congestion of the network (i.e. $P_{O}>0$ ) when applying Eq. 5, the surpluses are arranged in ascending order. While $\mathrm{P}_{\text {ATC }}(200 \mathrm{KW})$ is more than the minimum surpluses $(13 \mathrm{KW})$, the split unit discovered

Unit 6 (whose surplus value is $56 \mathrm{KW}$ ) is found to be the split one. Now the candidate in both left and right sides of the split unit will be determined. By knowing $\mathrm{P}_{\mathrm{E}}=16 \mathrm{KW}$ derived from Eq. (8), Unit 2 whose surplus value $31 \mathrm{KW}$ is the only one candidate in left side of the split unit (Lines 21-22). Unit 6 whose surplus value $56 \mathrm{KW}$ is selected to be the candidate in right side of the split unit (Lines 25-26). At the end, unit 6 is removed and substituted by unit 2 without override the limit of the capacity, i.e.

$$
\sum_{\mathrm{n}=1}^{5} \mathrm{P}_{\mathrm{S}, \mathrm{n}}=160 \leq \mathrm{P}_{\mathrm{ATC}}
$$

The results of applying the proposed knapsack GA are show in Table 1 which shows the selected units to be disconnected. It's shown that unit (6) is selected to be disconnected at $P_{\text {ATC }}=200 \mathrm{kw}$ keeping more units connected to the grid and minimum tariff for the connected units.

Table 1. Selected Unit by Greedy Algorithm at (PATC $=200 K W$ )

\begin{tabular}{c|c|c|c}
\hline Units number & $\begin{array}{c}\text { Surpluses } \\
(\mathrm{kw})\end{array}$ & $\begin{array}{c}\text { Tariff } \\
(\mathrm{pt})\end{array}$ & Selected units \\
\hline 1 & 13 & 40 & 1 \\
2 & 31 & 50 & 1 \\
3 & 34 & 60 & 1 \\
4 & 41 & 70 & 1 \\
5 & 41 & 80 & 1 \\
6 & 56 & 120 & 0 \\
\hline
\end{tabular}


In another case as shown in Table 2 , for $\mathrm{P}_{\mathrm{ATC}}=60 \mathrm{KW}$, unit 3 is found to be the split one (with surplus value $30 \mathrm{KW}$ ) while the first two units have sum of surplus values of 50 . Adding the value of split surplus will make the total 80 and result in overload. By knowing $\mathrm{P}_{\mathrm{E}}=20$, unit 1,2 are determined to be candidates in left side of split unit. Subsequently, the outcomes when searching for candidates in right side of split unit are units 3, 4. As a result, the selected units are 1,4 without override the limit of the capacity i.e. $P_{\mathrm{S}, 1}+\mathrm{P}_{\mathrm{S}, 4}$ $=60 \leq \mathrm{P}_{\text {ATC }}$.

In this situation the selected units are 1 and 4 whose tariff is 60,20 . But it is obvious from the Table II that, when selecting units 2,3 will not exceed the limit of the capacity, i.e. $\mathrm{P}_{\mathrm{S}, 2}+\mathrm{P}_{\mathrm{S}, 3}=60 \leq \mathrm{P}_{\mathrm{ATC}}$, since their tariff, 30, 40 respectively. This would be a better solution; therefore, the GA is not an optimum solution. So we will present the PSO algorithm for searching the best solution.

Table 2. Selected Unit by Greedy Algorithm at $(\mathrm{PATC}=60 \mathrm{KW})$

\begin{tabular}{c|c|c|c}
\hline Units number & $\begin{array}{c}\text { Surpluses } \\
(\mathrm{kw})\end{array}$ & $\begin{array}{c}\text { Tariff } \\
(\mathrm{pt})\end{array}$ & Selected units \\
\hline 1 & 20 & 60 & 1 \\
2 & 30 & 30 & 0 \\
3 & 30 & 40 & 0 \\
4 & 40 & 20 & 1 \\
5 & 60 & 70 & 0 \\
6 & 70 & 40 & 0 \\
\hline
\end{tabular}

\section{Particle Swarm Optimization (PSO)}

The PSO algorithm was developed by Kennedy and Eberhart [19]. It is inspired by the social movement of a swarm of birds searching for food. The algorithm is simple, easy to implement, powerful and robust [20]. The algorithm works by the presence of a swarm of particles. These particles are moved to a good region searching for food. The particles movements are guided by their own best known place with definite speed in the search-space. The velocity can be regulated dynamically due to its personal flying experience and flying experience of other particles. Better positions are discovered; these will then come to guide the movements of the swarm. The particle have two capabilities, their memory of their own best position - local best $\left(\mathrm{P}_{\mathrm{b}}\right)$ and knowledge of the global or their neighborhood's best-global best $\left(\mathrm{g}_{\mathrm{b}}\right)$ [21]. The position and velocity of particle $i^{\text {th }}$ are represented as $X_{i}=\left(x_{i 1}, x_{i 2}, x_{i D}\right)$ and $V_{i}=\left(v_{i 1}, v_{i 2}, v_{i D}\right)$, the best position is called $\mathrm{p}_{\text {best }}$ and the best position among the whole population called $\mathrm{g}_{\text {best }}$. Particles update their speeds and positions according to (8) and (9) until they find two extreme points as shown in Fig.3.

$$
\begin{aligned}
& \mathrm{v}_{\mathrm{i}}(\mathrm{t}+1)=\mathrm{W} \mathrm{v}_{\mathrm{i}}(\mathrm{t})+\mathrm{c}_{1}\left(\mathrm{p}_{\text {best }}(\mathrm{t})-\mathrm{x}_{\mathrm{i}}(\mathrm{t})\right)+\mathrm{c}_{2}\left(\mathrm{~g}_{\text {best }}(\mathrm{t})-\mathrm{x}_{\mathrm{i}}(\mathrm{t})\right) \\
& \mathrm{x}_{\mathrm{i}}(\mathrm{t}+1)=\mathrm{x}_{\mathrm{i}}(\mathrm{t})+\mathrm{v}_{\mathrm{i}}(\mathrm{t}+1)
\end{aligned}
$$

Where,

$\mathrm{i} \quad$ is the particle index

w is the inertial coefficient

$\mathrm{c}_{1}, \mathrm{c}_{2} \quad$ are acceleration coefficients, $0 \leq \mathrm{c}_{1}, \mathrm{c}_{2} \leq 2$

$\mathrm{r}_{1}, \mathrm{r}_{2} \quad$ are random values $\left(0 \leq \mathrm{r}_{1}, \mathrm{r}_{2} \leq 1\right)$ 


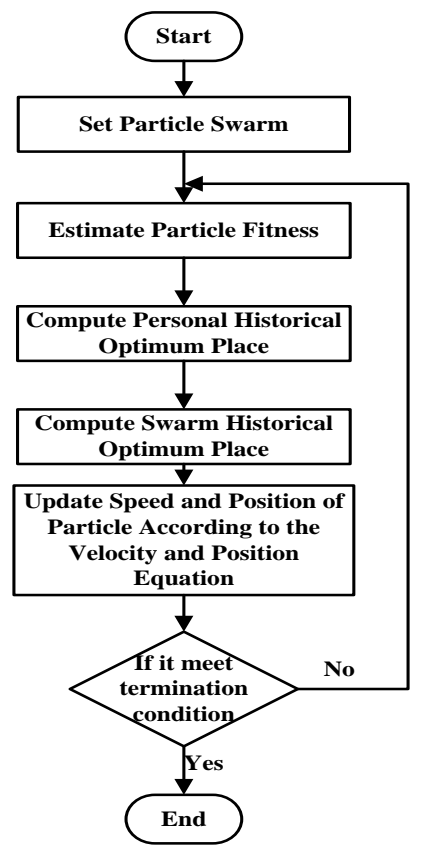

Fig. 3.Flow chart depicting the general PSO algorithm

The particle swarm for $\mathrm{P}_{\text {ATC }} \leq 60$ comparing with Greedy Algorithm is shown in Table 3.

Table 3. Case 1, Selected Units by PSO and GA.

\begin{tabular}{c|c|c|c|c}
\hline Units number & $\begin{array}{c}\text { Surpluses } \\
(\mathrm{KW})\end{array}$ & $\begin{array}{c}\text { Tariff } \\
(\mathrm{pt})\end{array}$ & $\begin{array}{c}\text { Selected units by } \\
\text { greedy }\end{array}$ & $\begin{array}{c}\text { Selected units by } \\
\text { PSO }\end{array}$ \\
\hline 1 & 30 & 20 & 1 & 1 \\
2 & 30 & 30 & 1 & 1 \\
3 & 40 & 40 & 0 & 0 \\
4 & 50 & 20 & 0 & 0 \\
5 & 60 & 70 & 0 & 0 \\
6 & 70 & 40 & 0 & 0 \\
\hline
\end{tabular}

Table 3 shows the same selection for both algorithms. The PSO for other surpluses and tariffs with the same $\mathrm{P}_{\text {ATC }} \leq 60$ comparing with Greedy Algorithm is shown in Table 4. The result shows that the selected units with PSO are with minimum tariff more than the units selected with Greedy Algorithm.

Table 4. Case2, Selected Units by PSO and GA.

\begin{tabular}{c|c|c|c|c}
\hline Units number & $\begin{array}{c}\text { Surpluses } \\
(\mathrm{KW})\end{array}$ & $\begin{array}{c}\text { Tariff } \\
(\mathrm{pt})\end{array}$ & $\begin{array}{c}\text { Selected units by } \\
\text { greedy }\end{array}$ & $\begin{array}{c}\text { Selected units by } \\
\text { PSO }\end{array}$ \\
\hline 1 & 20 & 60 & 1 & 0 \\
2 & 30 & 30 & 0 & 1 \\
3 & 30 & 40 & 0 & 1 \\
4 & 40 & 20 & 1 & 0 \\
5 & 60 & 70 & 0 & 0 \\
6 & 70 & 40 & 0 & 0 \\
\hline
\end{tabular}




\section{Conclusions and Future Work}

In this paper, congestion resulting from the PV surplus in the distribution network is relieved by disconnecting some solar units. PV surplus congestion was formulated as one type of knapsack problems (0/1 KP) and resolved by greedy strategies. Maximizing the number of connected units on the grid with minimal tariffs is the paper's goal. This goal is partially achieved by using the GA. The GA is compared with the PSO technique. The result shows that PSO is better for searching for the optimum solution.

\section{References}

[1] Basha AAJ. Transmission congestion management in restructured power system using firefly algorithm. Int. J. Comput. Appl, 2014; 85:39-43.

[2] Guguloth Ramesh TKSK. Congestion management in a deregulated power system with micro grid. Int. J. Electr. Comput. Energ. Electron. Commun. Eng, 2013; 7(11):1460-1464.

[3] Singh K, Yadav VK, Padhy NP, Sharma J. Congestion management considering optimal placement of distributed generator in deregulated power system networks. Electr. Power Components Syst, 2014; 42(1):13-22.

[4] Singh G. Transmission system congestion relief management by congestion relief charge in gaming condition. in Conf. on Advances in Electronics, Electrical and Computer Science Engineering, 2012:978-981.

[5] Huang S, Wu Q, Liu Z, and Nielsen AH. Review of congestion management methods for distribution networks with high penetration of distributed energy resources. IEEE Innov. Smart Grid Technol. Eur, 2014:1-6.

[6] V. A. J. Congestion Management in Deregulated Power Market - A Review. Int. Conf. Adv. Emerg. Technol. (ICAET ) Congest, 2016:18-23.

[7] Rajathy R, Kumar H, Engineering E. Power flow tracing based congestion management using differential evolution in deregulated electricity market. International Journal on Electrical Engineering and Informatics, 2012;4(2):371-392.

[8] Patel KK, Patel NK. Generation rescheduling for congestion management using relative electrical distance. J. Information, Knowl. Res. Electr. Eng, 2013;2(2):271-276.

[9] V. P. Sakthivel and S. V Vijayasundaram. Chaotic particle swarm optimization for congestion management in an electricity market. Int. J. Sci. Res. Publ, 2014;4(6):1-6.

[10] Reddy KRS, Padhy NP, and Patel RN. Congestion management in deregulated power system using FACTS devices, Power India Conf. 2006, 2(6).

[11] Rao MN. Congestion management in deregulated power system using facts controller. Int. J. Eng. Res. Gen. Sci, 2014;2(6):653-661.

[12] Poullikkas A. A review of net metering mechanism for. Int. J. Energy Environ, 2013;4(6):975-1002.

[13] EgyptERA. Renewable Energy - Feed- in Tariff Projects' Regulations. 2014.

[14] Gao S. Qiu L, and Cao C. Estimation of distribution algorithms for knapsack problem. J. Softw, 2014;9(1):104-110.

[15] Samanta S, Chakraborty S., Acharjee V, Mukherjee A, Dey N. Solving 0/1 knapsack problem using ant weight lifting algorithm. IEEE Int. Conf. Comput. Intell. Comput. Res. IEEE ICCIC, 2013:1-5.

[16] Pradhan T, Israni A, Sharma M. Solving the 0-1 Knapsack Problem Using Genetic Algorithm and Rough Set Theory. IEEE Int. Conf. Adv. Commun. Control Comput. Technol, 2014;(978):1120-1125.

[17] Bhesdadiya RH and Patel RM. Available transfer capability calculation methods: A review. Int. J. Adv. Res. Electr. Electron. Instrum. Energy, 2014; 3(1): 1-6.

[18] Lo C, Member S, and Ansari N. in the Distribution Grid via Smart Metering Communications. Parallel Distrib. Syst. IEEE, 2012;23(9):1607-1620.

[19] Kennedy J, Eberhart R. Particle swarm optimization. IEEE International Conference on Particle swarm optimization, 1995; 4: 1942-1948.

[20] Wen Long WZ, Shaohong C, Jianjun J. A hybrid constrained optimization approach coupling PSO and adaptive constraint-handling technique. WSEAS Trans. CIRCUITS Syst, 2016;15:55-63.

[21] Rahman MA, Islam MZ. A Hybrid Clustering Technique Combining A PSO Algorithm with K-Means. Int. J. Comput. Appl, 2014;71(1):345-365. 